\title{
Association between activity energy expenditure and peak oxygen consumption with sarcopenia
}

\author{
Daniel Bunout ${ }^{*}$ D, Gladys Barrera, Sandra Hirsch, Teresa Jimenez and María Pia de la Maza
}

\begin{abstract}
Background: Sedentariness may be an important risk factor for sarcopenia. The aim of this work was to assess the association between muscle mass and strength and markers of usual physical activity such as activity energy expenditure and peak oxygen uptake.

Methods: Young and old participants were assessed measuring body composition by DEXA (double beam X ray absorptiometry), handgrip strength, peak oxygen consumption and workload during an exercise calorimetry in a braked cycle ergometer and a $72 \mathrm{~h}$ activity energy expenditure using Actiheart actigraphs. A heart rate/energy expenditure curve derived from the exercise calorimetry was used to calibrate each actigraph. Sarcopenia was defined as having an appendicular fat free mass index below $7.5 \mathrm{~kg} / \mathrm{m}^{2}$ and $5.6 \mathrm{~kg} / \mathrm{m}^{2}$ in men and women respectively, or a handgrip strength z score below 1, using local normal data or having both parameters below the cutoff points.

Results: We analyzed data from 192 assessments performed in participants aged 22 to 88 years (106 women). Sarcopenic participants (as determined by muscle mass, strength or both) had a significantly lower peak oxygen uptake and work load and a significantly lower activity energy expenditure. When analyzing lean mass and strength as continuous variables, peak oxygen consumption was a significant predictor of fat free mass in men. Among women, the association was observed only when percentage of muscle mass was expressed as a z score.
\end{abstract}

Conclusions: Activity energy expenditure and peak oxygen consumption are associated with a lower muscle mass and the presence of sarcopenia and should be considered as risk factors for this condition.

Keywords: Sarcopenia, Sedentariness, Peak oxygen consumption, Actigraphy

\section{Background}

Sarcopenia or the loss of muscle mass and function may occur in any moment of life, but old age is a risk factor and a condition in which its functional consequences are more striking. There are many pathogenic hypotheses to explain the loss of muscle mass. Among these, sedentariness is always mentioned, but its real association with sarcopenia both in young and old people has not been fully tested.

If sedentariness has a pathogenic role on sarcopenia, this factor should be equally important in young and old people (defined as subjects aged 60 years or more), and there should be an association between usual physical

\footnotetext{
* Correspondence: dbunout@inta.uchile.cl

Institute of Nutrition and Food Technology, University of Chile, PO Box 138-11, Santiago, Chile
}

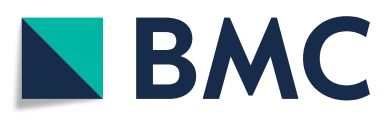

(c) The Author(s). 2018 Open Access This article is distributed under the terms of the Creative Commons Attribution 4.0 International License (http://creativecommons.org/licenses/by/4.0/), which permits unrestricted use, distribution, and

reproduction in any medium, provided you give appropriate credit to the original author(s) and the source, provide a link to the Creative Commons license, and indicate if changes were made. The Creative Commons Public Domain Dedication waiver (http://creativecommons.org/publicdomain/zero/1.0/) applies to the data made available in this article, unless otherwise stated. ies looking for this association. Park et al. found an association between year-long physical activity measured using pedometers and muscle mass in older people [1]. A further study by the same authors following older people for five years showed that the loss muscle mass in the study period was also associated with sedentariness determined using accelerometry [2]. There are several cross sectional studies that confirm this association [3].

An accurate method to measure usual physical activity is to determine activity energy expenditure. Doubly labeled water is the gold standard, however it is extremely expensive. An alternative is the use of actigraphy, whose accuracy increases when heart rate is also measured and is calibrated with individual heart rate/activity curves. There is a good concordance between doubly labeled 
water measurements and actigraphy with heart rate determination [4]. However some authors suggest that wearable devices lack accuracy [5].

The measurement of peak oxygen consumption by indirect calorimetry gives a precise estimation of the aerobic capacity of an individual. It is proportional to the usual physical activity and a direct indicator of fitness. Although it is influenced by age and genetic factors, usual physical activity is one of its main determinants [6]. Previous reports showed a direct association between muscle mass and peak oxygen consumption, speculating that a lower amount of metabolically active tissue would explain this association. However it is also possible to asseverate that a lower fitness derived from sedentariness, causes a reduction in muscle mass [7]. Therefore this parameter should provide an objective measurement that is inversely associated with long term sedentariness.

\section{Methods}

With the hypothesis that sedentariness is a main determinant of sarcopenia, the aim of this study was to evaluate whether daily physical activity and maximum oxygen consumption are determinants of muscle mass and function, regardless of age.

We analyzed data obtained from healthy volunteers participating in several studies on body composition, exercise capacity and aging. When the participants signed the informed consent to participate in the aforementioned studies, they allowed us to use their data in secondary analyses. Subjects living in the community aged 22 to 88 years were included. For all studies, we excluded participants with chronic debilitating diseases such as cancer, renal or cardiac failure or chronic infections. Individuals who could not reach the clinic by their own means, were unable to understand and sign the consent form or those who admitted abnormal consumption of alcohol or illicit drugs, also were excluded.

All participants had the following assessments performed and recorded:

\section{Clinical assessment}

Clinical history and physical examination including measurement of blood pressure, weight, height, waist circumference and a questionnaire about usual physical activity (International Physical Activity Questionnaire or IPAQ) [8].

\section{Handgrip strength measurement}

Handgrip strength was measured using a Therapeutic Instruments (Clifton NJ, United State) dynamometer. Three measurements were made in each hand and the higher value obtained for either hand was recorded. The measurement error of this parameter in repeated assessments in the same individual was $8.7 \%$.

\section{Body composition assessment}

Measurement of body composition by double beam $\mathrm{X}$ ray absorptiometry (DEXA) using a Lunar iDEXA equipment. Subjects were fasting at the moment of the assessment and had a normal fluid intake the previous day. A normal hydration status was confirmed clinically, looking for the absence of dehydration signs, peripheral edema or orthostatic hypotension. GE (General Electric) software version 13.6 was used. The measurement error of the method for body composition is $2.9 \%$ in our hands [9].

\section{Indirect calorimetry}

Submaximal oxygen consumption after an incremental test in a braked cycle ergometer was measured using a Sensormedics Vmax Encore 29 equipment. The incremental exercise test was started at a 10-watt ramp with 10-watt increases per minute or a 15-watt ramp with 15-watt increases (depending on age and the self-reported physical condition of participants) until volitional exhaustion, with a cadence of $60 \mathrm{rpm}$. The test was stopped if the participant could not maintain the cadence after the stage change or if the respiratory exchange ratio exceeded 1.3 [10]. A facemask was used to collect respiratory gases and the breath by breath method was used to measure oxygen consumption and $\mathrm{CO}_{2}$ production. Peak oxygen consumption was determined at the moment in which the participant was not able to maintain the cycling cadence. Gross work efficiency was calculated as the ratio between work rate and energy expended in joules multiplied by 100, at submaximal work rates [11]. To test the reproducibility of the measurement, we repeated the test within one month in 20 participants. The rho for concordance of two peak oxygen consumption measurements carried out in the same individual was 0.8 . The mean peak oxygen consumption values in the first and second measurements were $20.7 \pm 6$ and $20.8 \pm 7 \mathrm{ml} / \mathrm{min} / \mathrm{kg}$.

\section{Seventy two hours actigraphy}

An actigraph (Actiheart ${ }^{\circ}$ ) was installed to all participants for $72 \mathrm{~h}$ during weekdays for actigraphy and heart rate measurement. The devices were individually calibrated with the heart rate/energy expenditure curve obtained during the exercise calorimetry. The individual correlation between energy expenditure and heart rate in participants was $0.88 \pm 0.07$. Total energy expenditure (TEE), activity energy expenditure (AEE) and physical activity level (PAL) were determined (Actiheart software version 4.0.32, www.camntech.com).

\section{Data analysis and statistical methods Definition of sarcopenia}

Using body composition data obtained by DEXA, appendicular fat free mass index was calculated dividing appendicular fat free mass/height $(m)^{2}$. The cutoff point for this 
Table 1 Features of studied participants

\begin{tabular}{|c|c|c|c|c|c|}
\hline & $\begin{array}{l}\text { Young women } \\
\text { (A) }(n=65)\end{array}$ & $\begin{array}{l}\text { Old women } \\
\text { (B) }(n=41)\end{array}$ & $\begin{array}{l}\text { Young men } \\
\text { (C) }(n=58)\end{array}$ & $\begin{array}{l}\text { Old men (D) } \\
(n=28)\end{array}$ & $\begin{array}{l}\text { Significant } \\
\text { differences }\end{array}$ \\
\hline \multicolumn{6}{|l|}{ Demographic and clinical data } \\
\hline Age (years) & $36.2 \pm 9.0^{a}$ & $70.9 \pm 5.2$ & $36.2 \pm 7.7$ & $69.1 \pm 7.1$ & \\
\hline Body mass index $\left(\mathrm{kg} / \mathrm{m}^{2}\right)$ & $28.9 \pm 1.8$ & $29.0 \pm 4.4$ & $29.8 \pm 2.0$ & $27.5 \pm 3.1$ & C vs D \\
\hline Waist circumference (cm) & $90.0 \pm 5.7$ & $99.6 \pm 11.2$ & $100.9 \pm 6.0$ & $98.8 \pm 9.0$ & $A$ vs B C D \\
\hline Systolic blood pressure $(\mathrm{mm} \mathrm{Hg})$ & $115.5 \pm 10.7$ & $128.5 \pm 14.3$ & $122.8 \pm 9.6$ & $131.8 \pm 16.5$ & A vs C D C vs D \\
\hline Diastolic blood pressure (mm Hg) & $75.1 \pm 8.7$ & $71.5 \pm 10.0$ & $75.2 \pm 7.7$ & $82.1 \pm 11.0$ & NS \\
\hline Handgrip strength (kg) & $25.0 \pm 4.4$ & $19.4 \pm 4.1$ & $42.3 \pm 7.6$ & $28.5 \pm 5.6$ & All groups different \\
\hline Handgrip strength (z score) & $0.88 \pm 1.60$ & $-0.35 \pm 0.80$ & $0.17 \pm 1.57$ & $-0.79 \pm 1.18$ & A vs D C vs D \\
\hline \multicolumn{6}{|l|}{ Body composition (DEXA) } \\
\hline Total fat free mass $(\mathrm{kg})$ & $38.48 \pm 2.92$ & $35.46 \pm 4.07$ & $56.40 \pm 5.96$ & $47.97 \pm 6.40$ & All groups different \\
\hline Total fat mass (kg) & $30.99 \pm 3.76$ & $30.24 \pm 8.07$ & $29.84 \pm 4.76$ & $24.04 \pm 5.40$ & $D$ vs $A B C$ \\
\hline Appendicular fat free mass (kg) & $16.00 \pm 1.52$ & $14.10 \pm 2.24$ & $24.86 \pm 2.97$ & $19.61 \pm 3.28$ & All groups different \\
\hline Appendicular fat free mass index (kg/m2) & $6.44 \pm 0.50$ & $6.04 \pm 0.92$ & $8.33 \pm 0.84$ & $7.14 \pm 0.93$ & All groups different \\
\hline Appendicular fat mass (kg) & $13.30 \pm 2.34$ & $12.29 \pm 3.42$ & $10.51 \pm 2.18$ & $7.92 \pm 1.78$ & $\begin{array}{l}\text { A vs CD B vs } \\
C D C \text { vs D }\end{array}$ \\
\hline Percentage of skeletal muscle mass (\%) & $25.59 \pm 1.88$ & $22.96 \pm 2.03$ & $32.59 \pm 2.39$ & $29.53 \pm 1.80$ & All groups different \\
\hline Appendicular fat free mass (z score) & $0.66 \pm 0.80$ & $0.43 \pm 1.15$ & $0.76 \pm 0.90$ & $-0.02 \pm 1.14$ & D vs $A C$ \\
\hline Percentage of skeletal muscle mass (z score) & $-0.38 \pm 0.70$ & $-0.12 \pm 0.70$ & $-0.33 \pm 0.79$ & $-0.33 \pm 0.51$ & D vs A \\
\hline \multicolumn{6}{|l|}{ International physical activity questionnaire } \\
\hline Total physical activity (MET-minutes/week) & $630(264-1252)^{b}$ & $1155(531-2346)$ & $1173(626-1944)$ & $1179(544-2071)$ & $A$ vs B C D \\
\hline \multicolumn{6}{|l|}{ Exercise calorimetry } \\
\hline Peak oxygen uptake (ml/min/kg) & $17.6 \pm 4.2$ & $8.5 \pm 2.3$ & $25.6 \pm 5.8$ & $12.0 \pm 3.2$ & All groups different \\
\hline Peak respiratory exchange ratio $\left(\mathrm{VCO}_{2} \mathrm{NO}_{2}\right)$ & $1.3 \pm 0.1$ & $1.3 \pm 0.2$ & $1.3 \pm 0.2$ & $1.3 \pm 0.2$ & NS \\
\hline Peak workload (Watt) & $121.9 \pm 30.5$ & $41.0 \pm 18.6$ & $208.9 \pm 50.3$ & $66.1 \pm 21.4$ & All groups different \\
\hline Gross muscle efficiency (\%) & $26.0 \pm 6.3$ & $19.3 \pm 7.8$ & $24.4 \pm 3.2$ & $19.5 \pm 4.2$ & D vs AC \\
\hline \multicolumn{6}{|l|}{ Seventy two hours actigraphy } \\
\hline $\begin{array}{l}\text { Physical activity level } \\
\text { (Total/Resting energy expenditure) }\end{array}$ & $1.51 \pm 0.23$ & $1.39 \pm 0.17$ & $1.83 \pm 0.41$ & $1.59 \pm 0.16$ & $\begin{array}{l}\text { A vs } C D B \text { vs } \\
C D C \text { vs } D\end{array}$ \\
\hline Activity energy expenditure (Kcal/day) & $530(380-837)$ & $287(211-380)$ & $1047(679-1702)$ & $653(541-695)$ & $\begin{array}{l}A \text { vs } B C B \text { vs } \\
C D C \text { vs } D\end{array}$ \\
\hline
\end{tabular}

${ }^{\mathrm{a}}=$ mean \pm standard deviation ${ }^{\mathrm{b}}=$ median (interquartile range)

parameter used to determine sarcopenia was a value below $7.5 \mathrm{~kg} / \mathrm{m}^{2}$ in men and $5.6 \mathrm{~kg} / \mathrm{m}^{2}$ in women as we have recently proposed [12], following a recommendation made by a Brazilian group of researchers [13]. Appendicular fat free mass and fat free mass index were also expressed as $\mathrm{z}$ scores, calculated for decade of age (from 20 to 90 years) and sex, using the normal body composition data from our laboratory [11]. Skeletal muscle mass was also estimated using the equation proposed by Kim et al. [14] as [1.13 $\mathrm{x}$ appendicular fat free mass $]-[0.02 \mathrm{x}$ age $]+[0.61 \mathrm{x} \mathrm{sex}] 165$ +0.97 (sex: female $=0$, male $=1$ ). The percentage of skeletal muscle mass was then calculated as appendicular fat free mass $^{*}$ 100/skeletal muscle mass.

Handgrip strength was transformed to sex and age-specific $\mathrm{z}$ scores and a value below 1 was defined as indicative of sarcopenia. To obtain normal values for hand grip strength, we used measurements performed in 366 healthy subjects aged 20 to 89 years ( 255 females), as previously reported [15]. The mean value for each parameter and its standard deviation were calculated for each gender in ten year intervals from 20 years of age to over 80 years.

We classified participants as sarcopenic using three criteria: having an appendicular fat free mass index or a handgrip strength below their cutoff points or having both parameters below their cutoff points. We compared sarcopenic and non-sarcopenic participants, using these three different criteria. We also treated body composition and handgrip strength data as continuous variables and included them in multiple regression models. In these models, the independent variables added were age, peak oxygen uptake, gross 
Table 2 Features of participants with and without sarcopenia

\begin{tabular}{|c|c|c|c|c|c|c|}
\hline & \multicolumn{2}{|l|}{ Women } & \multirow[b]{2}{*}{$p$} & \multicolumn{2}{|l|}{ Men } & \multirow[b]{2}{*}{$p$} \\
\hline & $\begin{array}{l}\text { Without } \\
\text { sarcopenia }\end{array}$ & $\begin{array}{l}\text { With } \\
\text { sarcopenia }\end{array}$ & & $\begin{array}{l}\text { Without } \\
\text { sarcopenia }\end{array}$ & $\begin{array}{l}\text { With } \\
\text { sarcopenia }\end{array}$ & \\
\hline \multicolumn{7}{|c|}{ Sarcopenia defined as an appendicular lean body mass index cutoff point 5.6 for women and 7.5 for men and a handgrip $z$ score $<-1$} \\
\hline Number of participants & 101 & 5 & & 75 & 11 & \\
\hline Total physical activity (MET-minutes/week) ${ }^{c}$ & $742(330-1589)^{b}$ & $495(438-1836)$ & NS & $1244(693-2139)$ & $594(258-1836)$ & NS \\
\hline Peak oxygen uptake $(\mathrm{ml} / \mathrm{min} / \mathrm{kg})^{d}$ & $14.4 \pm 5.6^{\mathrm{a}}$ & $7.0 \pm 2.2$ & $<0.01$ & $22.0 \pm 8.3$ & $15.6 \pm 3.7$ & 0.02 \\
\hline Peak respiratory exchange ratio $\left(\mathrm{VCO}_{2} \mathrm{NO}_{2}\right)^{d}$ & $1.3 \pm 0.1$ & $1.4 \pm 0.1$ & NS & $1.3 \pm 0.2$ & $1.3 \pm 0.2$ & NS \\
\hline Peak workload (Watt) ${ }^{d}$ & $93.2 \pm 47.2$ & $38.4 \pm 9.8$ & 0.01 & $171.1 \pm 79.3$ & $103.0 \pm 56.5$ & $<0.01$ \\
\hline Gross muscle efficiency (\%) ${ }^{d}$ & $23.5 \pm 7.7$ & $23.0 \pm 6.9$ & NS & $23.0 \pm 3.8$ & $21.8 \pm 6.7$ & NS \\
\hline Physical activity level (Total/Resting energy expenditure) ${ }^{\mathrm{e}}$ & $1.47 \pm 0.22$ & $1.33 \pm 0.12$ & NS & $1.77 \pm 0.38$ & $1.57 \pm 0.18$ & NS \\
\hline Activity energy expenditure (Kcal/day) ${ }^{\mathrm{e}}$ & $445(282-646)$ & $221(149-331)$ & 0.03 & $926(590-1533)$ & $649(447-706)$ & 0.04 \\
\hline \multicolumn{7}{|c|}{ Sarcopenia defined as an appendicular lean body mass index cutoff point 5.6 for women and 7.5 for men } \\
\hline Number of participants & 88 & 18 & & 58 & 28 & \\
\hline Total physical activity (MET-minutes/week) & $731(325-1570)^{b}$ & $808(372-2319)$ & NS & $1152(678-2333)$ & $1248(454-1981)$ & NS \\
\hline Peak oxygen uptake $(\mathrm{ml} / \mathrm{min} / \mathrm{kg})$ & $15.2 \pm 5.5$ & $8.8 \pm 3.5$ & $<0.01$ & $24.1 \pm 7.7$ & $15.1 \pm 5.2$ & $<0.01$ \\
\hline Peak respiratory exchange ratio $\left(\mathrm{VCO}_{2} \mathrm{NO}_{2}\right)$ & $1.3 \pm 0.1$ & $1.3 \pm 0.2$ & NS & $1.3 \pm 0.2$ & $1.3 \pm 0.2$ & NS \\
\hline Peak workload (Watt) & $100.5 \pm 44.9$ & $42.1 \pm 25.2$ & $<0.01$ & $194.6 \pm 70.2$ & $95.8 \pm 53.3$ & $<0.01$ \\
\hline Gross muscle efficiency (\%) & $24.1 \pm 7.5$ & $19.9 \pm 7.2$ & 0.03 & $23.5 \pm 3.5$ & $21.4 \pm 5.3$ & 0.03 \\
\hline Physical activity level (Total/Resting energy expenditure) & $1.5 \pm 0.2$ & $1.4 \pm 0.2$ & NS & $1.8 \pm 0.4$ & $1.6 \pm 0.3$ & NS \\
\hline Activity energy expenditure (Kcal/day) & $461(285-742)$ & $304(221-416)$ & $<0.01$ & $1008(635-1619)$ & $671(541-811)$ & $<0.01$ \\
\hline \multicolumn{7}{|l|}{ Sarcopenia defined as a z score for handgrip strength $<=-1$} \\
\hline Number of participants & 61 & 45 & & 63 & 23 & \\
\hline Total physical activity (MET-minutes/week) & $742(264-1928)$ & $720(400-1589)$ & NS & $1547(738-2346)$ & $693(330-1695)$ & $<0.01$ \\
\hline Peak oxygen uptake $(\mathrm{ml} / \mathrm{min} / \mathrm{kg})$ & $12.7 \pm 5.4$ & $16.0 \pm 5.6$ & $<0.01$ & $22.6 \pm 8.4$ & $17.4 \pm 6.2$ & $<0.01$ \\
\hline Peak respiratory exchange ratio $\left(\mathrm{VCO}_{2} \mathrm{NO}_{2}\right)$ & $1.3 \pm 0.1$ & $1.3 \pm 0.1$ & NS & $1.3 \pm 0.1$ & $1.3 \pm 0.2$ & NS \\
\hline Peak workload (Watt) & $77.4 \pm 45.0$ & $108.4 \pm 45.5$ & $<0.01$ & $175.9 \pm 78.6$ & $125.4 \pm 72.6$ & $<0.01$ \\
\hline Gross muscle efficiency (\%) & $22.3 \pm 8.4$ & $24.9 \pm 6.2$ & NS & $23.3 \pm 3.7$ & $21.7 \pm 5.4$ & NS \\
\hline Physical activity level (Total/Resting energy expenditure) & $1.4 \pm 0.2$ & $1.5 \pm 0.3$ & NS & $1.8 \pm 0.4$ & $1.6 \pm 0.3$ & 0.02 \\
\hline Activity energy expenditure (Kcal/day) & $367(250-555)$ & $517(295-754)$ & NS & $951(613-1619)$ & $665(448-943)$ & 0.01 \\
\hline
\end{tabular}

${ }^{\mathrm{a}}=$ mean \pm standard deviation $^{\mathrm{b}}=$ median (interquartile range)

${ }^{c}=$ International physical activity questionnaire. ${ }^{d}=$ Exercise calorimetry. ${ }^{e}=72 \mathrm{~h}$ actigraph

work efficiency (as described earlier), physical activity level derived from actigraphy and total physical activity derived from IPAQ questionnaire. We were especially careful to avoid including independent variables that were highly correlated, to avoid biases in the regression model.

For analysis purposes, participants were divided according to age, in young ( $<60$ years) and old $(>=60$ years) groups. This is the age used to define older people in Chile. All subsequent comparisons and regression models were performed separately for men and women, considering the striking gender differences in muscle strength and mass. Normality of variable distribution was assessed using the Shapiro Wilk test. Variables with a normal distribution are expressed as mean \pm standard deviation and otherwise as median (interquartile range). Parametric statistical tests such as $\mathrm{t}$ test were used to compare normally distributed variables. Otherwise, we used non-parametric tests such as Kruskal Wallis anova. For the multiple regression models a p of 0.1 was used as cutoff to accept or remove variables from the model.

\section{Results}

Data from 192 assessments performed in participants aged from to 22 to 88 years (106 women) were analyzed. Table 1 shows clinical, body composition, exercise calorimetry and actigraphy features of participants, divided by gender and age range. Women and older people had lower fat free mass, handgrip strength, peak oxygen consumption and workload and activity energy expenditure. Young women reported a total physical activity in the physical activity questionnaire, which was significantly lower than the rest of the groups. The respiratory exchange ratio of 1.3 in all 


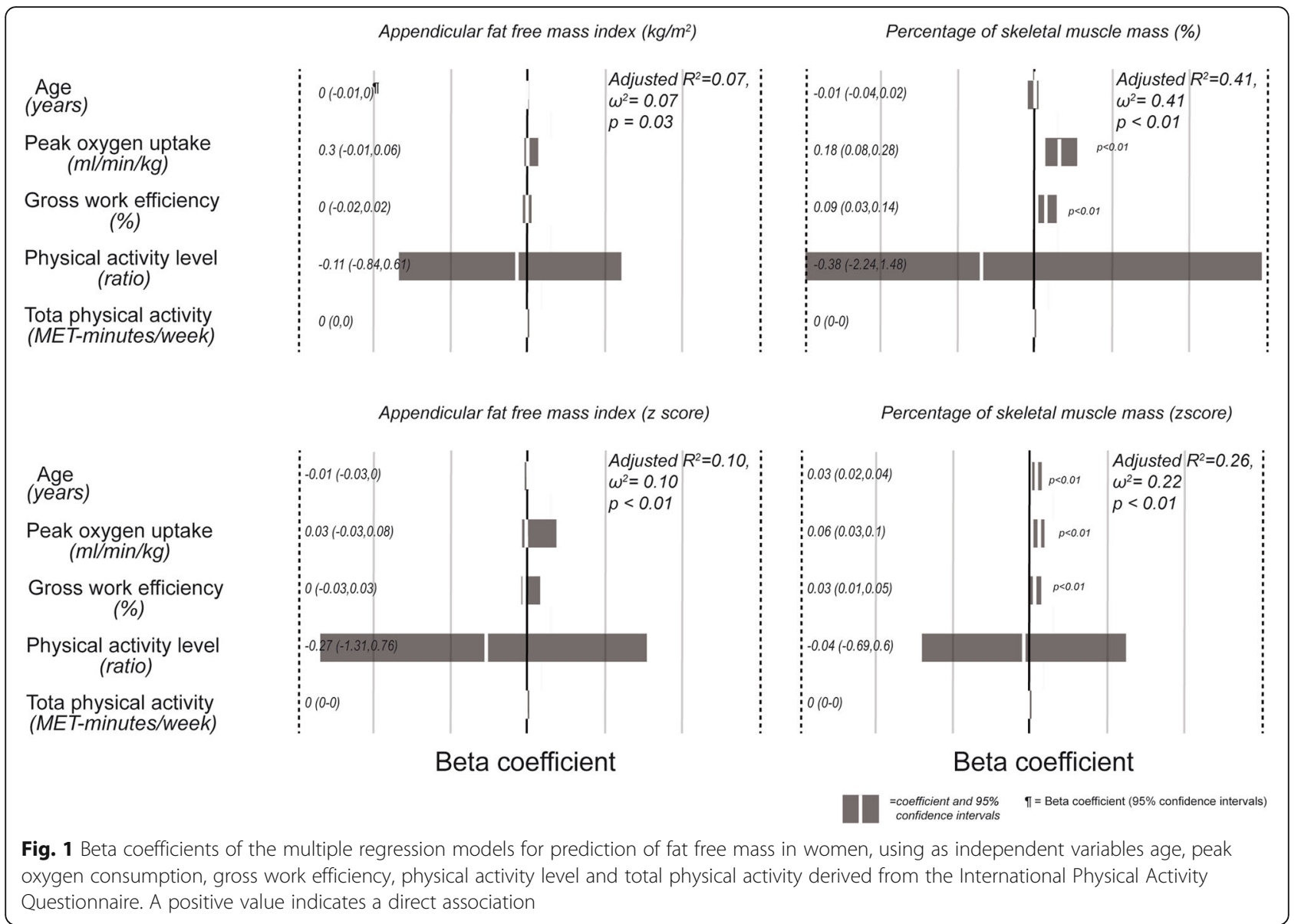

groups is an indication that real peak values were achieved during the exercise calorimetry. There was a significant correlation between peak oxygen uptake and activity energy expenditure measured by actigraphy, both in women and men $(r=0.53$ and 0.37 respectively, $p<0.01)$. There was also a significant correlation between peak oxygen consumption and fat free mass in women and men $(r=$ 032 and 0.62 respectively, $\mathrm{p}<0.01$ ). There was no association between total physical activity measured using the International Physical activity questionnaire and peak oxygen uptake or activity energy expenditure.

Table 2 compares men and women according to the presence of sarcopenia, defined using body composition, strength criteria or both. Peak oxygen consumption and work load and $72 \mathrm{~h}$ activity energy expenditure were lower in sarcopenic participants, whatever definition used. When sarcopenia was defined using only strength criteria, no differences in activity energy expenditure were observed between sarcopenic women and their non-sarcopenic counterparts.

Figures 1 and 2 show the regression models for appendicular fat free mass index and percentage of muscle mass, expressed as absolute values or $\mathrm{z}$ scores, for women and men. In general, the models had a higher $r^{2}$ in men than women. In the former, peak oxygen consumption was always a significant and independent predictor of muscle mass. Among women, beta coefficients of peak oxygen consumption were only significant when fat free mass was expressed as percentage of skeletal muscle mass. Although the regressions are significant, the effect size of the models for men and women is low to intermediate, with $\mathrm{r}^{2}$ and $\omega^{2}$ values ranging from 0.07 to 0.52 . In all models, except for the percentage of skeletal muscle mass expressed as z score in men, age was not a significant predictor of fat free mass.

Figure 3 shows the results of the regression models when handgrip strength was the dependent variable. Again, the $r^{2}$ values were higher in men and peak oxygen consumption was a significant and independent predictor in most models. Gross work efficiency was a significant predictor or handgrip strength in almost all models. Beta coefficients of physical activity level were only significant for the percentage of skeletal muscle mass expressed as z score in men. Total physical activity, calculated using the physical activity questionnaire did not have any predictive value. As in the case of fat free mass, the effect size of the models for men and women is low, with $r^{2}$ and $\omega^{2}$ values ranging from 0.16 to 0.45 . 


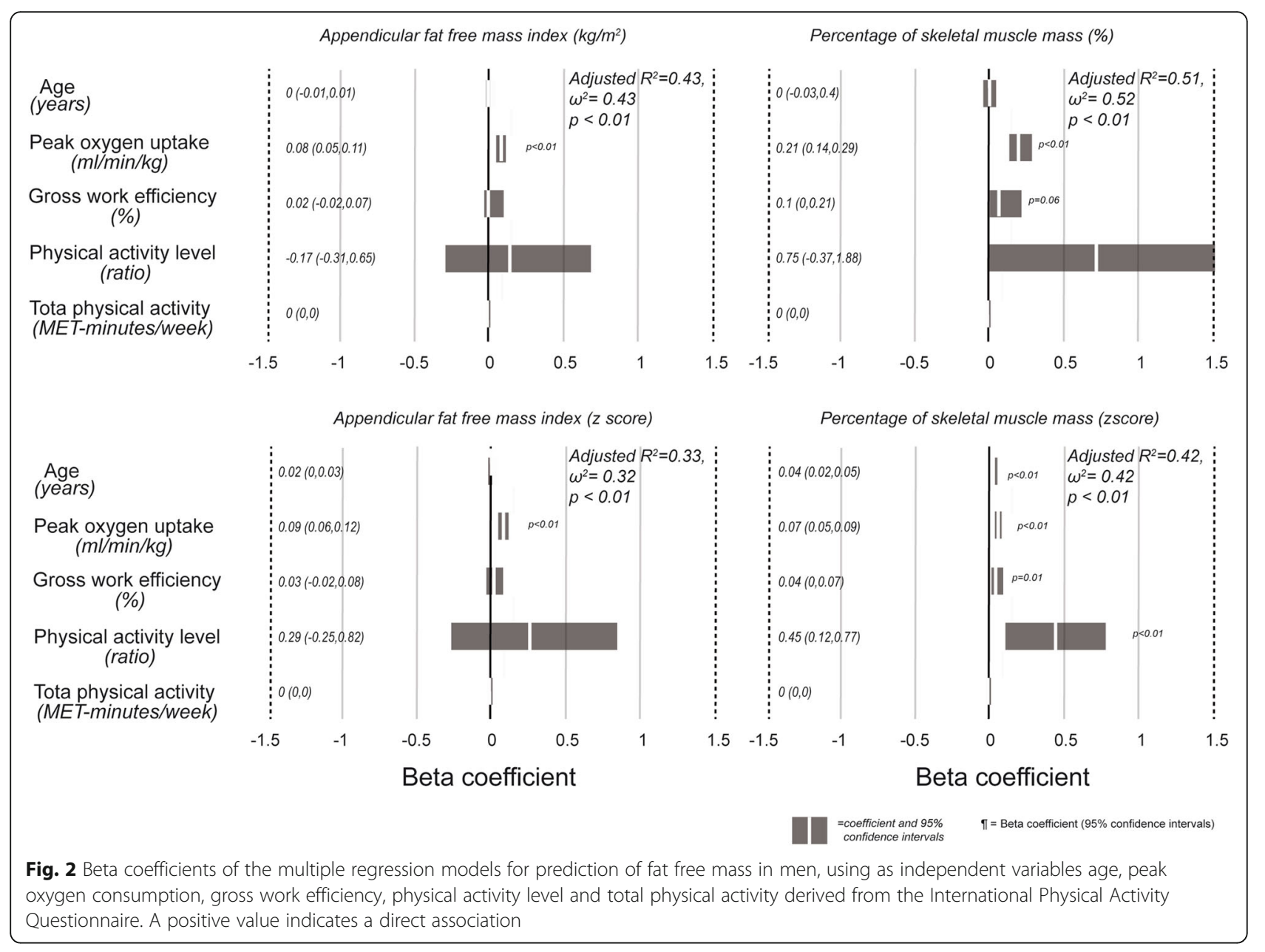

\section{Discussion}

We herein show that in young and old men and women, the presence of sarcopenia is associated with lower activity energy expenditure and a lower physical fitness, measured using an exercise calorimetry.

The definition of sarcopenia relies in the loss of muscle mass and function. We measured muscle mass using DEXA, which is accurate and reliable and accepted by most guidelines on sarcopenia [16]. Imaging methods such as magnetic resonance, ultrasound or computed tomography are also used, but their reliability is usually tested against DEXA [17]. The most widely used functional measure is handgrip strength, whose prognostic value is well established [18]. Therefore we used DEXA and handgrip strength to assess muscle mass and strength respectively. We have shown previously that both measures are predictive of mortality in our population of older subjects $[19,20]$. The cutoff of muscle mass used to define sarcopenia was set at 1 standard deviation from the normal value, determined in a large set of participants of the same genetic and socioeconomic background reported previously [12]. In that report, we showed that using one instead of two standard deviations provides a better approach to determine sarcopenia in our population. The same cutoff was proposed by a Brazilian group of investigators previously [21]. The cutoff values for handgrip strength were derived from a similar group of participants, to avoid any regional bias in the determination of sarcopenia.

When comparing participants with and without sarcopenia defined using mass, strength or both, it is noteworthy that in all cases, subjects with sarcopenia had a lower peak oxygen uptake and activity energy expenditure, except in women, when sarcopenia was defined only by using handgrip strength. The differences in peak oxygen uptake have been seldom reported. The aforementioned Brazilian authors, performed an exercise test in a subgroup of participants with and without sarcopenic obesity finding differences in absolute but not relative peak oxygen uptake [21]. A Japanese group found an association between estimated oxygen uptake and 


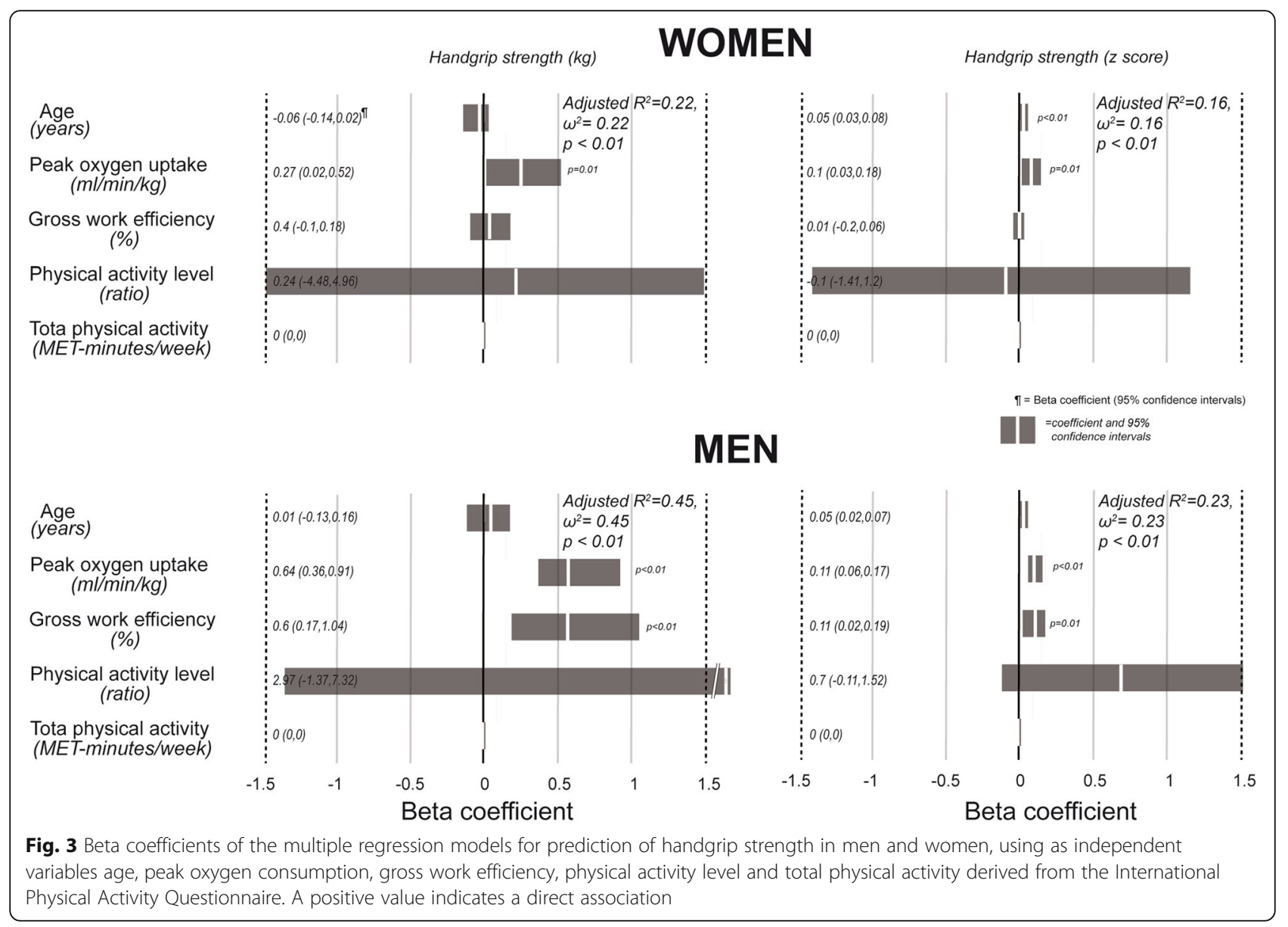

skeletal muscle mass in men and women [22]. It is well known that training improves peak oxygen uptake, even in older people [23], but we are reporting results from participants who have not been trained. Thus, what we are observing are the effects of usual physical activity on this parameter [24], which is lower in participants with sarcopenia. There are several reports showing a lower activity energy expenditure in subjects with sarcopenia [25], therefore this finding is not surprising, but gives strength and reaffirms the differences found in peak oxygen uptake. On top of this, both peak oxygen consumption and usual physical activity are predictors of mortality healthy people [26, 27]. Thus, it is tempting to speculate if the prognostic value of sarcopenia on mortality is an independent effect or just a reflection of the higher level of sedentariness of people with this condition.

When muscle mass or strength were treated as a continuous variable in the multiple regression models, peak oxygen consumption was accepted as a significant predictor of fat free mass in men. In women the predictive capacity of this parameter was lower. These results reaffirm the concept that fitness is a protective factor against sarcopenia. The effect size of the regression equations was low, but they fulfill our purpose to show that physical fitness is related to the preservation of muscle mass across all ages. A report by Aggio et al. showed an association between sedentary time and the presence of severe sarcopenia, of a similar magnitude than the association herein reported [28]. A similar association was reported previously in older women. Surprisingly, the peak oxygen consumption values obtained by these authors were very similar to those obtained by us. However they interpreted the results, arguing that a lower muscle mass is the cause and not the consequence of a lower aerobic capacity [29]. Other authors also proposed this alternative hypothesis [30]. The only means of resolving is fitness or low muscle mass are the initiating event in the cascade of functional decline, is to perform longitudinal studies of cohorts, measuring the other factors that may affect aerobic capacity such as cardiovascular performance.

The association between handgrip strength and gross work efficiency is intuitively obvious, considering that both measures are a functional assessment of muscle. However, gross work efficiency and handgrip are 
assessing different muscular groups. This may be an indicator that a lower work efficiency is indicating an overall increase in the ATP cost for muscle contraction, phenomenon that is also associated with sarcopenia [31].

The International Physical Activity Questionnaire had no association with fat free mass. The lack of association of this parameter with peak oxygen uptake or activity energy expenditure, cast doubts about the accuracy of these types of questionnaires to objectively assess physical activity. Other authors report a significant albeit very low concordance between these type of questionnaires and data derived from accelerometry [32, 33]. Therefore, the interpretation of results obtained from these questionnaires should be very cautious and probably reserved only for large scale epidemiological studies. Using this questionnaire, we observed that young women had a lower total physical activity than the other participants. However this observation was not confirmed with Actigraphy, a much more accurate method.

The two main weaknesses of this study is that it is cross sectional and not having used doubly labeled water to assess activity energy expenditure. The latter is unsurmountable since the cost of doubly labeled water is too high. The former should encourage us to follow the participants of this cohort and perform a new assessment in the future to confirm is the actual loss of muscle mass, the essential aspect of sarcopenia, is associated with usual physical activity.

Our main strengths are that we studied both young and older people, showing that sarcopenia effectively occurs in young subjects and that physical activity is a risk factor for it in all age ranges. Also it is important to highlight that all comparisons were made separately by gender, avoiding the confounding effect of the striking differences in body composition and muscle strength between men and women [34]. It should also be pointed out that we used objective and accurate measures of physical activity such as accelerometry and cardiopulmonary exercise testing.

\section{Conclusions}

Sedentariness is associated with sarcopenia in this group of participants and should be considered as an important risk factor for this condition.

\section{Abbreviations}

AEE: Activity energy expenditure; DEXA: Double beam X ray absorptiometry; GE: General Electric; IPAQ: International Physical Activity Questionnaire; PAL: Physical activity level; TEE: Total energy expenditure

\section{Funding}

No external funding was used to carry out this study.

\section{Availability of data and materials}

The datasets used and/or analyzed during the current study are available from the corresponding author on reasonable request.

\section{Authors' contributions}

DB: Made substantial contributions to conception and design, or acquisition of data, or analysis and interpretation of data; was involved in drafting the manuscript or revising it critically for important intellectual content and gave the final approval of the version to be published. He agrees to be accountable for all aspects of the work in ensuring that questions related to the accuracy or integrity of any part of the work are appropriately investigated and resolved. GB: Made substantial contributions to conception and design, or acquisition of data, or analysis and interpretation of data; was involved in drafting the manuscript or revising it critically for important intellectual content and gave the final approval of the version to be published. She agrees to be accountable for all aspects of the work in ensuring that questions related to the accuracy or integrity of any part of the work are appropriately investigated and resolved. SH: Made substantial contributions to analysis and interpretation of data; was involved in drafting the manuscript or revising it critically for important intellectual content and gave the final approval of the version to be published. She agrees to be accountable for all aspects of the work in ensuring that questions related to the accuracy or integrity of any part of the work are appropriately investigated and resolved. TJ: Made substantial contributions to acquisition of data, taking care of most participants in the study, calculated energy expenditure and oxygen consumption values, contributed to data analysis and gave the final approval of the version to be published. She agrees to be accountable for all aspects of the work in ensuring that questions related to the accuracy or integrity of any part of the work are appropriately investigated and resolved. MPDLM: Made substantial contributions to analysis and interpretation of data; was involved in drafting the manuscript or revising it critically for important intellectual content and gave the final approval of the version to be published. She agrees to be accountable for all aspects of the work in ensuring that questions related to the accuracy or integrity of any part of the work are appropriately investigated and resolved. All authors read and approved the final manuscript.

\section{Ethics approval and consent to participate}

All the studies in which subjects included in this work participated, were approved by the Institute of Nutrition and Food Technology ethics committee. When participants signed their informed consent, they allowed the authors to use their data in secondary analyses.

\section{Consent for publication}

This manuscript does not contain any individual person's data.

\section{Competing interests}

The authors declare that they have no competing interests.

\section{Publisher's Note}

Springer Nature remains neutral with regard to jurisdictional claims in published maps and institutional affiliations.

Received: 24 May 2018 Accepted: 26 November 2018 Published online: 03 December 2018

\section{References}

1. Park H, Park S, Shephard RJ, Aoyagi Y. Yearlong physical activity and sarcopenia in older adults: The Nakanojo study. Eur J Appl Physiol. 2010;109: 953-61.

2. Shephard RJ, Park H, Park S, Aoyagi Y. Objectively measured physical activity and progressive loss of lean tissue in older Japanese adults: Longitudinal data from the Nakanojo study. J am Geriatr Soc. 2013;61:1887-93.

3. Liu P, Hao Q, Hai S, Wang H, Cao L, Dong B. sarcopenia as a predictor of allcause mortality among community-dwelling older people: A systematic review and meta-analysis. Maturitas. 2017;103:16-22.

4. Silva AM, Santos DA, Matias CN, Júdice PB, Magalhães JP, Ekelund U, Sardinha LB. Accuracy of a combined heart rate and motion sensor for assessing energy expenditure in free-living adults during a double-blind crossover caffeine trial using doubly labeled water as the reference method. Eur J Clin Nutr. 2015;69:20-7.

5. Murakami H, Kawakami R, Nakae S, Nakata Y, Ishikawa-Takata K, Tanaka S, Miyachi M. Accuracy of wearable devices for estimating Total energy expenditure: Comparison with metabolic chamber and doubly labeled water method. JAMA intern med. 2016;176:702-3. 
6. Mundwiler J, Schüpbach U, Dieterle T, Leuppi JD, Schmidt-Trucksäss A Wolfer DP, Miedinger D, Brighenti-Zogg S. Association of Occupational and Leisure-Time Physical Activity with aerobic capacity in a working population. PLoS one. 2017:12(1):e0168683.

7. Pourhassan M, Eggeling B, Schautz B, Johannsen M, Kiosz D, Glüer CC, BosyWestphal A, Müller MJ. Relationship between submaximal oxygen uptake, detailed body composition, and resting energy expenditure in overweight subjects. Am J hum biol. 2015;27:397-406.

8. Kim Y, Park I, Kang M. Convergent validity of the international physical activity questionnaire (IPAQ): Meta-analysis. Public health Nutr. 2013;16:440-52.

9. Gajardo H, Barrera G. Quality control of bone densitometry: Precision, reproducibility, and clinical application. Rev med Chil. 1998;126:56-62.

10. Balady GJ, Arena R, Sietsema K, Myers J, Coke L, Fletcher GF, et al. Clinician's guide to cardiopulmonary exercise testing in adults: A scientific statement from the American Heart Association. Circulation. 2010;122:191-225.

11. Moseley L, Jeukendrup AE. The reliability of cycling efficiency. Med Sci sports Exerc. 2001;33:621-7.

12. Wigodski S, Carrasco F, Bunout D, Barrera G, Hirsch S, De la Maza MP. Sarcopenia: The need to establish different cutting points of fat free mass. Nutrition. 2018;57:217-24.

13. Barbosa-Silva TG, Bielemann RM, Gonzalez MC, Menezes AM. Prevalence of sarcopenia among community-dwelling elderly of a medium-sized south American city: Results of the COMO VAl? Study. J Cachexia sarcopenia muscle. 2016;7:136-43

14. Kim J, Wang Z, Heymsfield S, Baumgartner R, Gallagher D. Total-body skeletal muscle mass: Estimation by a new dual-energy X-ray absorptiometry method. Am J Clin Nutr. 2002;76:378-83.

15. Canales E, Barrera G, Hirsch S, De la Maza MP, Bunout D. maximal expiratory pressure predicts mortality in patients hospitalized in medical and surgical wards. Nutricion Hospitalaria. 2018;35:683-8.

16. Cruz-Jentoft AJ, Baeyens JP, Bauer JM, Boirie Y, Cederholm T, Landi F, Martin FC, Michel JP, Rolland Y, Schneider SM, Topinková E, Vandewoude M, Zamboni M, European working group on sarcopenia in older people. Sarcopenia: European consensus on definition and diagnosis: Report of the European working group on sarcopenia in older people. Age ageing. 2010;39:412-23.

17. Berger J, Bunout D, Barrera G, de la Maza MP, Henriquez S, Leiva L, Hirsch S. rectus femoris (RF) ultrasound for the assessment of muscle mass in older people. Arch Gerontol Geriatr. 2015;61:33-8.

18. Leong DP, Teo KK, Rangarajan S, Lopez-Jaramillo P, Avezum A Jr, Orlandini A, Seron P, Ahmed SH, Rosengren A, Kelishadi R, Rahman O, Swaminathan S, lqbal R, Gupta R, Lear SA, Oguz A, Yusoff K, Zatonska K, Chifamba J, Igumbor E, Mohan V, Anjana RM, Gu H, Li W, Yusuf S. Prospective urban rural epidemiology (PURE) study investigators. Prognostic value of grip strength: Findings from the prospective urban rural epidemiology (PURE) study. Lancet. 2015:386:266-73.

19. Bunout D, de la Maza MP, Barrera G, Leiva L, Hirsch S. association between sarcopenia and mortality in healthy older people. Australas J ageing. 2011;30:89-92.

20. Bites A, Bunout D, Barrera G, Hirsch S, Leiva L, De la Maza MP. Association between functional measures and mortality in older persons. International journal of gerontology. 2013;7:17-21.

21. Oliveira R, Bottaro M, Junior J, Farinatti $P$, Bezerra L, Lima R. Identification of sarcopenic obesity in postmenopausal women: A cut off proposal. Braz J med biol res. 2011:44:1171-6.

22. Sanada K, Kuchiki T, Miyachi M, McGrath K, Higuchi M, Ebashi H. Effects of age on ventilatory threshold and peak oxygen uptake normalised for regional skeletal muscle mass in Japanese men and women aged 20-80 years. Eur J Appl Physiol. 2007;99:475-83.

23. Bouaziz W, Kanagaratnam L, Vogel T, Schmitt E, Dramé M, Kaltenbach G, Geny B, Lang PO. Effect of aerobic training on peak oxygen uptake among seniors aged 70 or older: A meta-analysis of randomized controlled trials. Rejuvenation res. 2018;21:341-9.

24. Aspenes ST, Nauman J, Nilsen TI, Vatten LJ, Wisløff U. Physical activity as a long-term predictor of peak oxygen uptake: The HUNT study. Med Sci sports Exerc. 2011:43:1675-9.

25. Steffl M, Bohannon RW, Sontakova L, Tufano JJ, Shiells K, Holmerova I. relationship between sarcopenia and physical activity in older people: A systematic review and meta-analysis. Clin Interv aging. 2017;12:835-45

26. Blair SN, Kampert JB, Kohl HW 3rd, Barlow CE, Macera CA, Paffenbarger RS $\mathrm{Jr}$, Gibbons LW. Influences of cardiorespiratory fitness and other precursors on cardiovascular disease and all-cause mortality in men and women. JAMA. 1996;276:205-10.
27. Manini TM, Everhart JE, Patel KV, Schoeller DA, Colbert LH, Visser M, Tylavsky F, Bauer DC, Goodpaster BH, Harris TB. Daily activity energy expenditure and mortality among older adults. JAMA. 2006;296:171-9.

28. Aggio DA, Sartini C, Papacosta O, Lennon LT, Ash S, Whincup PH, Wannamethee SG, Jefferis BJ. Cross-sectional associations of objectively measured physical activity and sedentary time with sarcopenia and sarcopenic obesity in older men. Prev med. 2016;91:264-72.

29. De Oliveira RJ, Bottaro M, Motta AM, Pitanga F, Guido M, Leite TK, Bezerra LM, Lima RM. Association between sarcopenia-related phenotypes and aerobic capacity indexes of older women. J sports Sci med. 2009;8:337-43.

30. Rosen MJ, Sorkin JD, Goldberg AP, Hagberg JM, Katzel LI. Predictors of ageassociated decline in maximal aerobic capacity: A comparison of four statistical models. J Appl Physiol (1985). 1998;84:2163-70.

31. Layec G, Hart CR, Trinity JD, Le Fur Y, Jeong EK, Richardson RS. Skeletal muscle work efficiency with age: The role of non-contractile processes. Clin Sci (Lond). 2015;128:213-23.

32. Silsbury Z, Goldsmith R, Rushton A. Systematic review of the measurement properties of self-report physical activity questionnaires in healthy adult populations. BMJ open. 2015;5(9):e008430.

33. Garriguet D, Tremblay S, Colley RC. Comparison of physical activity adult questionnaire results with accelerometer data. Health rep. 2015;26:11-7.

34. Bunout D, de la Maza MP, Barrera G, Leiva L, Gattas V, Hirsch S. assessment of sarcopenia: Longitudinal versus cross sectional body composition data. Aging Clin Exp res. 2007;19:295-9.

\section{Ready to submit your research? Choose BMC and benefit from:}

- fast, convenient online submission

- thorough peer review by experienced researchers in your field

- rapid publication on acceptance

- support for research data, including large and complex data types

- gold Open Access which fosters wider collaboration and increased citations

- maximum visibility for your research: over $100 \mathrm{M}$ website views per year

At BMC, research is always in progress.

Learn more biomedcentral.com/submissions 